\title{
Correction to: Isolation and genotyping of novel T4 cyanophages associated with diverse coral reef invertebrates
}

\author{
Alex J. Veglia ${ }^{1,2}$ (1) Caleb R. Milford ${ }^{3} \cdot$ Nikolaos V. Schizas $^{1}$
}

Published online: 8 February 2021

(c) Springer-Verlag GmbH Germany, part of Springer Nature 2021

\section{Correction to: Coral Reefs \\ https://doi.org/10.1007/s00338-021-02056-3}

This erratum is published due to formatting discrepancies noticed with figures and tables overlooked by vendor during proofing.
The original article has been updated.

Publisher's Note Springer Nature remains neutral with regard to jurisdictional claims in published maps and institutional affiliations.

The original article can be found online at https:// doi.org/10.1007/s00338-021-02056-3.

Alex J. Veglia

alex.veglia@gmail.com

1 Department of Marine Sciences, University of Puerto Rico at Mayagüez, PO Box 9000, Mayagüez, PR 00681, USA

2 Department of Biosciences, Rice University, 6100 Main St., Houston, TX 77005, USA

3 Department of Biology and Marine Biology, Roger Williams University, Bristol, RI 02809, USA 